\title{
BELEZA EM 140 CARACTERES: UM ESTUDO SOBRE O COMPORTAMENTO DO CONSUMIDOR DE COSMÉTICOS BRASILEIROS NO TWITTER ${ }^{1}$
}

\section{BEAUTY IN 140 CHARACTERS: A STUDY ON THE CONSUMER BEHAVIOR OF BRAZILIAN COSMETICS ON TWITTER}

\author{
Cárlei Nunes Dellinghausen² \\ Tiago Savi Mondo ${ }^{3}$ \\ Jane Iara Pereira da Costa ${ }^{4}$
}

\begin{abstract}
RESUMO: O fenômeno da evolução das mídias sociais é assunto frequente nas conversas informais, na mídia impressa, na televisão e em sites corporativos. Essa nova realidade dinâmica da comunicação e das relações é motivo de curiosidade e investigação para a maioria das organizações. O presente estudo busca analisar qual o comportamento do consumidor de cosméticos nacionais no microblogging Twitter, referenciados pelo enfoque de quatro empresas do setor pelo período de quinze dias. Para a coleta e análise dos dados, utilizaram-se ferramentas disponíveis na Internet e conhecimentos da netnografia aplicados à pesquisa quantitativa. Os resultados obtidos da análise de 3772 postagens demonstram diferenças nos comentários sobre as empresas, forma de atuação, posicionamento de mercado, produtos mais mencionados, representativos do panorama do mercado de cosméticos no Brasil. Conclui-se que o conteúdo das mensagens postadas é mais positivo do que negativo e que cada empresa estabelece relacionamentos diferentes no canal de comunicação.
\end{abstract}

PALAVRAS-CHAVE: mídias sociais, comportamento do consumidor, Twitter, cosméticos, netnografia.

ABSTRACT: The phenomenon of social media trends is a frequent subject in informal conversations, in print, on television and on corporate websites. This new reality communication dynamics and relations is a matter of curiosity and research for most organizations. The present study seeks to examine what the consumer behavior of microblogging Twitter national cosmetics, referenced by the focus of four companies in the industry for a period of fifteen days. For the collection and analysis of data, used tools available on the Internet and knowledge of netnography applied to quantitative research. The results obtained from the analysis of 3772 posts demonstrate differences in comments about companies, form of performance, market positioning, more products mentioned, representing the cosmetic market panorama in Brazil. It is concluded that the contents of posted messages is more positive than negative, and that each company establishes different relationships in the communication channel.

KEY-WORDS: social media, consumer behavior, Twitter, cosmetics, netnography.

\footnotetext{
${ }^{1}$ Artigo Recebido em 07.10.2010. Revisado por pares em 12.09.2011. Recomendado em 14.03.2012 por Edson Roberto Scharf - Editor Responsável. Publicado em 13.06.2012.

Organização Responsável pelo periódico: Universidade Regional de Blumenau - FURB - www.furb.br/rn
}

\footnotetext{
${ }^{2}$ Universidade do Estado de Santa Catarina- UDESC - carleinunes@yahoo.com.br

${ }^{3}$ Universidade do Estado de Santa Catarina- UDESC - tiagomondo@gmail.com

${ }^{4}$ Universidade do Estado de Santa Catarina- UDESC - costajane@udesc.br
} 


\section{INTRODUÇÃO}

Antigamente as pessoas se encontravam nas praças das cidades para se atualizarem das novidades (DIMANTAS, 2008), depois vieram os meios de comunicação tradicionais, como o rádio e a televisão que trouxeram a informação ao lar. Não havia a necessidade de socializar para alcançar o conteúdo. As inter-relações foram ficando menos freqüentes. Hoje, com a Internet e as mídias sociais, a comunicação se dá de forma extremamente rápida, no lar, no local de trabalho, pelo celular e em outros meios e locais. As pessoas voltam a se comunicar de forma intensa, a ouvirem e serem ouvidas, inclusive diretamente com as empresas (DIMANTAS, 2008). Bilhões de pessoas conectadas em redes de comunicação conseguem ativamente participar da inovação e do desenvolvimento social de maneira considerada utópica há alguns anos atrás (TAPSCOTT, WILLIAMS, 2007).

Esse fenômeno emergente das mídias sociais mudou significativamente ou vai modificar as estratégias de comunicação organizacional business to consumer, e a imprensa comercial e a literatura acadêmica ainda não oferecem aos gestores de Marketing orientações ou sugestões para incorporar as mídias sociais ao seu mix de comunicação integrado (MANGOLD \& FAULDS, 2009). Dessa forma o estudo busca apresentar uma parcela do comportamento do consumidor e das empresas de cosméticos no Twitter, que é um canal de discussões e não só um meio de transmissão de informação. As companhias podem falar mais diretamente do que nunca com seus consumidores, parceiros e colaboradores, de forma pessoal e pública, algo que não se atinge em outro meio (O'REILLY, MILSTEIN, 2009).

A escolha da indústria brasileira de cosméticos como mercado alvo além do encanto da beleza e do bem estar, está atrelada a um mercado forte e representativo existente há mais de 3500 anos (DIAMOND, DIAMOND, 2008). A indústria brasileira de beleza ocupa mundialmente a terceira colocação no ranking mundial do setor, de acordo com dados de 2008, segundo a Associação Brasileira da Indústria de Higiene Pessoal, Perfumaria e Cosméticos (ABIHPEC, 2009). A mesma associação entende que o setor de perfumaria nacional atingirá, até 2013, a primeira colocação no mercado mundial. O Brasil detém uma fatia de $13,1 \%$ do mercado mundial, que representa o segundo lugar perdendo apenas para os Estados Unidos, que atingiu 14,5\% da participação em 2009 (ABIHPEC, 2010).

O objetivo principal do estudo é responder à seguinte pergunta:

O que dizem os consumidores de determinadas marcas de cosméticos brasileiras no Twitter?

Para tal, o referencial teórico aborda mídias sociais, elementos do Marketing e o setor de cosméticos. A pesquisa exploratória quantitativa aliada à pesquisa netnográfica para verificação de padrões de comportamento, têm os métodos abordados de forma minuciosa nos Procedimentos Metodológicos. Os resultados decorrentes do estudo, conciliados aos estudos científicos, originaram as conclusões adiante elencadas.

\section{REFERENCIAL TEÓRICO}

A seguir foram selecionados conceitos correlacionados com o problema objeto da pesquisa: comportamento do consumidor de quatro empresas de produção de cosméticos 


\section{BELEZA EM 140 CARACTERES: UM ESTUDO SOBRE O COMPORTAMENTO DO CONSUMIDOR DE COSMÉTICOS BRASILEIROS NO TWITTER}

brasileiras no Twitter - no intuito de conhecer e esclarecer as relações que se estabelecem neste meio.

\subsection{Redes Sociais e Mídias Sociais}

As relações sociais são alvo de estudo de pesquisadores das mais diversas áreas das ciências sociais desde o inicio do século XX, e perduram até os dias de hoje, com ênfase na Antropologia. Na década de 90 esse estudo obteve um novo fôlego quando o foco ampliou-se também para as redes sociais mediadas por meios eletrônicos, como computadores e celulares com acesso à Internet, com características dinâmicas e não estáticas (RECUERO, 2009; TELLES, 2010). Essas redes de relacionamento são compostas por dois elementos básicos que não podem ser isolados: os atores e suas conexões, sendo aqueles as pessoas, instituições ou grupos envolvidos e essas os laços sociais ou interações (RECUERO, 2009).

As equipes de gestão das organizações hoje precisam definir se vão incorporar ou não as mídias sociais ao seu mix de comunicação integrado (MANGOLD; FAULDS, 2009), o que modifica e aproxima a relação direta com o cliente da organização. Há a possibilidade das organizações falarem diretamente com seus clientes, parceiros e colaboradores, de forma pessoal e pública, o que inviável de outras formas (O’REILLY, MILSTEIN, 2009).

Confirmando o exposto sobre as relações que ocorrem nas mídias sociais, Mangold \& Faulds (2009, p. 358) defendem que neste meio as empresas mais têm a ganhar com a pesquisa de mercado que lhes é oferecida do que como forma de promoção de seus produtos e atividades:

"Em primeiro lugar, mídias sociais permitem que as empresas conversem com seus clientes e, segundo, elas possibilitam aos clientes falarem entre si. As mídias sociais também permitem aos clientes conversarem com as companhias; no entanto, este canal serve mais como uma pesquisa de mercado do que um canal de promoção..."

Papacharissi (2009, p. 201) por outro lado, realizou estudo comparativo da arquitetura e estrutura dos sites Facebook, LinkedIn e ASmallWorld e trata destas relações como "representações simbólicas das rotinas de comunicação diárias que as redes sociais criam para seus usuários". São diversas as formas de se analisar e perceber os movimentos criados nas mídias sociais, assim como muita dúvida e diferença na conceituação dos termos técnicos para cada relação ou meio de comunicação.

Garton, Haythornthwaite e Wellman (1997, p.1, tradução nossa) afirmam que uma rede social é caracterizada "quando uma rede de computadores conecta uma rede de pessoas e organizações".

Para definição do conteúdo considerado nessa pesquisa, decidiu-se por conveniência utilizar a definição de sites de relacionamento e mídias sociais de acordo com Telles (2010, p. 18 e 19):

"Sites de relacionamento ou redes sociais são ambientes cujo foco é reunir pessoas, os chamados membros, que uma vez inscritos, podem expor seu perfil com dados como fotos pessoais, textos, mensagens e 
vídeos, além de interagir com outros membros, criando listas de amigos e comunidades."

"As mídias sociais são sites na internet construídos para permitir a criação colaborativa de conteúdo, a interação social e o compartilhamento de informações em diversos formatos."

Para delimitação do escopo desse estudo, decidiu-se por conveniência utilizar o Twitter, acessível através do endereço eletrônico: www.twitter.com.

\subsection{Twitter}

O microblogging Twitter, dentro das mídias sociais, é um grande fenômeno, pois em 5 anos é conhecido e utilizado mundialmente em função de uma única pergunta: "O que está acontecendo?". Foi inaugurado em março de 2006 em São Francisco e a partir de então cresce de forma intensa (O'REILLY, MILSTEIN, 2009; TELLES, 2010). Funciona como um serviço de mensagens similar ao e-mail, MSN, blogs, com características que o individualizam, como: caráter público das mensagens com no máximo 140 caracteres, enviáveis por diferentes meios (telefones celulares, outras redes sociais, programas, dentre outras opções).

Os tweets ou posts, como são denominadas as mensagens postadas no Twitter, são informações fáceis de ler e de escrever e não necessitam de autorização para que sejam lidas (O'REILLY, MILSTEIN, 2009; TELLES, 2010). Para que se receba as informações de uma determinada pessoa, deve-se usar o sistema de opt-in, ou seja, seguir aquele emissor, sem que haja necessidade de autorização do mesmo. Caso uma mensagem enviada pelo sujeito A interesse ao sujeito B, esse pode repassar essa informação aos seus seguidores, através de uma ferramenta denominada RT, o retweet.

Conforme a visão de Vaz (2010, p. 433), o Twitter é "uma ferramenta de divulgação, um veículo de disseminação de informações e mensuração da 'infosfera' da internet. Funciona também como se fosse um e-mail marketing mais objetivo e segmentado". Percebe-se que há diferentes formas de uso das informações postadas no microblogging, seja como análise antropológica, estrutural ou mercadológica. Neste estudo, o enfoque é quanto ao posicionamento do cliente de determinadas empresas de produtos de higiene pessoal, perfumaria e cosméticos.

\subsection{Marca}

Marca é o ativo mais forte de uma organização pois, segundo Kotler (2000), é uma promessa de entrega de produtos e serviços com certo padrão de qualidade nos seus atributos, benefícios, valores, cultura e personalidade. Uma marca pode ser composta por produtos, serviços, lugares e pessoas (HEALEY, 2009) que complementa sua visão ao mencionar que

“marca é uma promessa de satisfação. É um sinal, uma metáfora que age como um contrato não escrito entre um produtor e um consumidor, 
um vendedor e um comprador, um ator e um público, um ambiente e os que o habitam, um evento e os que o experimentam".

O mesmo autor (HEALEY, 2009) infere que o branding, processo contínuo entre o produtor e o cliente nessa definição de promessa e significação, tem cinco componentes:

- Posicionamento, conforme a definição do cliente sobre a representatividade da marca e sua comparação com suas concorrentes;

- História, que representa a possibilidade de compartilhar com as histórias das marcas e delas fazer parte;

- $\quad$ Design, quanto ao que se pode criar e elaborar quanto ao produto ou serviço;

- $\quad$ Preço, que determina aspectos relevantes da concorrência; e

- Atendimento ao cliente, fundamental aos esforços de branding, ao buscar tornar cada cliente especial.

Já Kotler e Keller (2006, p. 270) entendem que o branding "diz respeito a criar estruturas mentais e ajudar o consumidor a organizar seu conhecimento sobre produtos e serviços, de forma que torne sua tomada de decisão mais esclarecida e, nesse processo, gere valor à empresa”.

Com abordagem relacionada às mídias sociais, Telles (2010, p. 19) afirma que "o social media marketing relaciona-se bem de perto com o branding (esforço da marca para atrair credibilidade, efeito memória e permanência junto ao mercado)".

Enquanto atua nas mídias sociais, todo contato feito pelas organizações de forma geral ou individualizada com clientes específicos, auxilia na formação dessa identidade perante o mercado. A imagem da marca será formada pelas experiências vividas com a organização.

\subsection{Mix de comunicação de Marketing}

Considerando as mídias sociais como um canal de relacionamento, há que se entender exatamente as maneiras possíveis de comunicação das empresas perante seus clientes. Kotler (2000) afirma que o mix de comunicação de Marketing tem cinco formas principais, que são propaganda, promoção de vendas, relações públicas, vendas pessoais e Marketing direto.

Esses elementos foram identificados nos tweets analisados sobre as empresas de cosméticos da seguinte forma:

Propaganda - inserida no item "imagem da marca", pois relaciona-se à comunicação institucional ou focada em produto específico, direcionada ao mercado.

Promoção de vendas - inclui tanto a promoção de vendas da empresa como a ação promocional envolvendo a marca por iniciativa de terceiros, fato corriqueiro nas mídias sociais.

Relações públicas - tem sua atividade atrelada ao item "relacionamento com cliente".

Marketing direto - considera a atração para outra mídia da empresa, através de links presentes nos tweets.

\subsection{Marketing de relacionamento}


É um assunto de abordagem inevitável ao se pesquisar as mídias sociais, posto que as mesmas se apresentam como canal de relacionamento inédito entre clientes e empresas. McKenna (1999) afirmou que na era da informação não é mais possível se fabricar uma imagem de marca, pois a distância entre percepção e realidade estava diminuindo. Assim, a relação cliente / organização / mercado deve ser especial, pois ativa o ciclo de feedback essencial para medição da resposta do mercado às características da empresa e seus produtos.

Ocorre que a expressão Marketing de Relacionamento, apesar de muito utilizada, não é voz comum entre os estudiosos. Um conceito mais clássico para Marketing de relacionamento é aquele que busca o relacionamento satisfatório tanto para a empresa quanto para seus clientes, fornecedores e distribuidores, que venha a construir uma rede de marketing a longo prazo (KOTLER, 2000, p. 51). Sob um prisma mais focado no consumidor, Stone e Woodstock $(1998$, p. 3) apresentam o seguinte conceito:

"Marketing de relacionamento é como nós:

1. Achamos você.

2. Passamos a conhecê-lo.

3. Mantemos contato com você.

4. Tentamos assegurar que você obtenha de nós aquilo que quer - não apenas em termos de produto mas também em todos os aspectos do nosso relacionamento com você.

5. Verificamos se você está obtendo aquilo que lhe prometemos. Desde que, naturalmente, isso também seja vantajoso para nós."

Para essa análise, considerou-se Marketing de relacionamento como a relação construída pelo diálogo entre cliente e empresa defendidos por McKenna (1999) ao prever que os mercados se transformariam em nichos determinados em infra-estruturas nítidas com comunicação mais direta. Também serviram de base para esta investigação as obras de Telles (2010) que sugerem às empresas que ouçam o que se diz nas redes sociais, blogs e microbloggings no intuito de satisfazer às necessidades do cliente interagindo com o mesmo. Ainda, Telles (2006) menciona que os canais tradicionais de relacionamento com o cliente (SACs, sites corporativos) têm perdido espaço com o advento das mídias sociais, cujo fluxo de informações têm crescido em ordem inversa.

\subsection{Mercado de cosméticos}

A indústria brasileira do setor de higiene pessoal, perfumaria e cosméticos tem destaque mundial com a terceira posição no ranking mundial no ano de 2008. Segundo a ABIHPEC (2010), na época havia mais de 1700 empresas atuantes no setor, sendo 15 de grande porte, oportunizando mais de 60 mil postos de trabalho diretos e mais de três milhões indiretos (COMPORTAMENTO FEMININO, 2010).

$\mathrm{O}$ crescimento em 15 anos das oportunidades de trabalho no setor da higiene pessoal, perfumaria e cosméticos foi na ordem de $112,3 \%$ na indústria e de $189 \%$ nas franquias (ABIHPEC, 2010). O setor de maquiagem nacional movimentou US\$2,17 bilhões, o que 


\section{BELEZA EM 140 CARACTERES: UM ESTUDO SOBRE O COMPORTAMENTO DO CONSUMIDOR DE COSMÉTICOS BRASILEIROS NO TWITTER}

representou participação de 5,1\% no mercado mundial (ABIHPEC, 2010). O mercado nacional do setor de produtos para as unhas detém 10,1\% do mercado mundial, o que lhe garante segunda colocação, atrás apenas do consumo de produtos para as unhas nos Estados Unidos - 16,6\% (ABIHPEC, 2010).

Além de um contexto atraente que envolve beleza e bem-estar, a "indústria da beleza" brasileira tem relevância significativa no contexto nacional e mundial.

\section{PROCEDIMENTOS METODOLÓGICOS}

A presente pesquisa alia a pesquisa netnográfica à pesquisa quantitativa e tem como características intrínsecas ser exploratória, descritiva e comparativa, por buscar compreender um problema de acordo com critérios estabelecidos e disseminar as informações obtidas sistematicamente (MALHOTRA, 2006). O primeiro passo para o início das atividades foi a constatação da pergunta-problema - o que se encontra no Twitter quando pesquisadas determinadas marcas do mercado nacional de cosméticos? A partir de então, procurou-se desenvolver a estrutura mais coerente para a abordagem dos dados primários - os tweets - que têm alta carga subjetiva, pois são informações sobre impressões, anseios e concepções humanas.

\subsection{Netnografia}

Uma das formas de pesquisa nas ciências sociais, com grande ênfase de seu uso na antropologia e no estudo do comportamento do consumidor, é a etnografia que, segundo Vergara (2008, p. 72), “consiste na inserção do pesquisador no ambiente, no dia-a-dia do grupo investigado" para entender os valores explícitos e implícitos no grupo, tendências de comportamento, dentre outros. Com a ampliação das relações mediadas por computador, Kozinets $(2007,287)$ adaptou a etnografia à cibercultura, cunhando o termo "netnografia" ao pesquisar as relações existentes nas comunidades virtuais ao final dos anos 1990 e defende sua utilização por aspectos diversos:

"... netnografia pode informar ao marketing e à publicidade sobre as intenções e significados mais profundos da experiência de consumo de carne e osso. Ela pode iluminar motivos, esperanças, medos e sonhos, em uma distância que permite e atende plenamente ao inesperado e ao real. "

O pesquisador pode se posicionar perante o objeto pesquisado de forma altamente participativa ou meramente observacional. Kozinets (2001) argumenta que não há uma rigidez na composição da pesquisa netnográfica, mas indica quatro procedimentos metodológicos não estáticos para a configuração da mesma:

- Entrée cultural: preparação para o trabalho de pesquisa pelo pesquisador, com a definição dos assuntos que deseja analisar e inserção no meio através das comunidades e sites;

- Coleta e análise dos dados: a coleta pode ser de três formas (cópia das conversações nas comunidades online, observação das práticas 
comunicacionais dos membros das comunidades e dados levantados individualmente por meio de entrevistas)

- Ética de pesquisa: identificação do pesquisador como tal e objetivos da pesquisa

- Feedback e checagem de informações com os membros das comunidades: ação que legitima e dá credibilidade ao trabalho.

Diante do exposto, a presente pesquisa apresenta características da pesquisa netnográfica por:

- inserção aprofundada dos pesquisadores no universo dos cosméticos e do Twitter;

- coleta de dados públicos ao se arquivar diariamente as informações disponibilizadas;

- utilização da ética como elemento norteador de todo o trabalho sem a necessidade de se identificar os pesquisadores perante os emissores dos comentários, visto que não são um grupo social específico, mas usuários que citaram em seus tweets as marcas pesquisadas. Para preservação da imagem individual dos usuários da mídia social, adotamos a nomeação usuário (a) conforme a indicação do gênero apresentado no perfil - adicionado a um número sequencial indicador da ordem em que são apresentados. No caso da empresa de cosméticos, nos reservamos o direito de expor seu nome e posicionamento, visto que auxilia no entendimento e identificação dos dados.

Aliada a essa pesquisa qualitativa, determinou-se que a categorização dos dados seria feita com características da pesquisa quantitativa, para identificar comportamentos padrão na mídia social.

\subsection{As empresas pesquisadas}

Foram definidas aleatoriamente, quatro marcas de empresas de cosméticos nacionais para foco de análise, as quais são apresentadas de acordo com as informações obtidas em seus sites oficiais:

- Akakia

Lançada durante a Feira da Associação Brasileira de Franchising de 2005. Em 2010, a empresa tem 140 pontos de vendas e, em 2007, foi a franquia de cosméticos que mais cresceu no país. Busca oferecer produtos de qualidade com preços acessíveis e uma marca focada no consumidor jovem. Foi extinta em 2011 ao ser vendida ao grupo Água de Cheiro.

\section{- O Boticário}

Em 1977 foi inaugurada a primeira farmácia de manipulação em Curitiba, Paraná. Em 1979 lançada a fragrância Acqua Fresca que se tornou ícone da empresa. Em 1980 inaugurouse a primeira franquia, em Brasília. Em 1985 eram 500 lojas em todo o Brasil. Reconhecida pela qualidade na perfumaria, estrutura e empreendedorismo em premiações nacionais e internacionais.

\section{- Contém 1g}


Fundada no ano de 1984 em São Paulo, com foco em produtos para maquiagem. Em 2000 abriu espaço para franquias, em 2010 são mais de 200 pontos de venda. A proposta da marca é ensinar suas consumidoras a se maquiarem. Trata a profissional da equipe de vendas como maquiadora-vendedora e lhe proporciona cursos de maquiagem em diferentes níveis.

\section{- Granado}

Em 1870 estabeleceu-se a primeira Granado, que é hoje a botica mais antiga do Brasil. Inicialmente eram manipulados produtos a base de plantas cultivadas no sítio do fundador. Em 1880 Dom Pedro II a consagrou como a Farmácia Oficial da Família Real Brasileira. Sua primeira filial foi inaugurada 60 anos após sua inauguração. A empresa busca trabalhar com preceitos de sustentabilidade e responsabilidade social. Em 2010, além da loja virtual a empresa conta com cinco unidades comerciais.

\subsection{Coleta de dados}

A coleta de dados foi viabilizada pela ferramenta oficial do Twitter, o sistema Advanced Search (http://search.twitter.com/advanced), de acordo com os seguintes critérios preenchidos a cada busca:

\begin{tabular}{|l|l|}
\hline Critérios apresentados pela ferramenta de busca & Opção preenchida \\
\hline All of these words & akakia / boticario / contem 1g / granado \\
\hline Language & Português \\
\hline Places within the distance & 1000 miles (maior distância apresentada) \\
\hline Since this date & 4 a 18 de julho 2010 \\
\hline Results per Page & 50 (persistent) \\
\hline
\end{tabular}

Quadro 1: Preenchimento dos filtros de busca do Twitter Advanced Search

Fonte: Twitter Advanced Search

Os dados do Twitter obtidos no Advanced Search são públicos pelo período de cinco dias seguintes após a emissão. Findo esse prazo, as informações não são mais disponibilizadas. Os dados utilizados para o desenvolvimento deste estudo foram publicados no microblogging mencionado e estavam acessíveis a todo e qualquer interessado. As empresas citadas no presente estudo são constantemente expostas a análises de suas ações e têm seus nomes veiculados pela mídia em geral.

\subsection{Tratamento dos dados}

Com os dados coletados, procedeu-se à necessidade de elaborar instrumento para tabulação e quantificação dos mesmos. Esse instrumento passou a ser alvo de testes e diversos ajustes. Várias perguntas foram feitas e, ao final, foram definidos os elementos considerados:

- Origem da mensagem.

- Gênero do emissor.

- Comportamento identificado.

- Citação de elemento do Mix de Marketing.

- Menção a elemento do mix de produtos. 
- Caráter promocional ou Link para outra mídia.

Cada uma das questões aplicadas e suas características estão elucidadas nos Quadros 2 a 8 que seguem:

A primeira definição feita retrata quem emitiu a mensagem, conforme Quadro 2:

\begin{tabular}{|l|l|}
\hline Origem da mensagem & Perfil(s) da empresa no Twitter. \\
\hline A empresa de cosméticos & $\begin{array}{l}\text { Qualquer emissor que não a empresa de cosméticos } \\
\text { analisada }\end{array}$ \\
\hline A rede / consumidores
\end{tabular}

Quadro 2: Origem da mensagem

Para mensagens emitidas pela empresa de cosméticos, observou-se que pode ser considerado mais de um perfil, como exemplo diferentes franqueadas.

A aparente indicação do gênero do emissor da mensagem também foi levada em conta, conforme Quadro 3:

\begin{tabular}{|l|l|}
\hline Gênero aparente do emissor da mensagem \\
\hline Feminino & Masculino \\
\hline Pessoa Jurídica & Sem indicação \\
\hline
\end{tabular}

Quadro 3: Tipo de emissor da informação

No caso do tweet, o emissor é aquele que assina a mensagem. No retweet/RT o emissor original da mensagem é aquele cuja mensagem foi reproduzida.

Para registrar esses dados foram criados balizadores considera-se que na comunicação mediada pela tecnologia dos computadores, há visível distanciamento e não há como se ter certeza do gênero das pessoas, apenas consideram-se as representações dos atores sociais (RECUERO, 2009). O critério utilizado neste estudo para determinar o gênero de quem supostamente gerou a informação ocorreu pela observação do nome e da foto, ou um deles que dê indícios de feminino, masculino ou pessoa jurídica. Em caso de dúvida marcou-se o item "sem indicação".

A definição do comportamento do consumidor ou da empresa emissora da informação buscou uma ampla gama de percepções (posicionamentos positivo ou negativo), declaração ou intenção de compra de produtos, dúvida, indicação da marca sem posicionamento, expectativa, sugestão da marca como interessante pela ferramenta Follow Friday ou mesmo piadas e saudações. O Quadro 4 explica cada uma das variáveis comportamentais com as características consideradas.

\begin{tabular}{|l|l|}
\hline Comportamento identificado & Elogio, boa experiência, agradecimento \\
\hline Posicionamento positivo & $\begin{array}{l}\text { Reclamação, experiência ruim, relativa a diferentes aspectos } \\
\text { (produto, marca, comunicação, relacionamento, promoção) }\end{array}$ \\
\hline Posicionamento negativo & $\begin{array}{l}\text { Aquisição, presentes, teste. Caso o post contenha declaração de } \\
\text { compra aliada a posicionamento positivo do produto, esse último } \\
\text { prevalece }\end{array}$ \\
\hline $\begin{array}{l}\text { Declaração de compra, uso ou } \\
\text { recebimento }\end{array}$ & Vontade de adquirir ou ganhar algum produto da marca \\
\hline $\begin{array}{l}\text { Intenção de compra, uso ou } \\
\text { recebimento }\end{array}$ & \\
\hline
\end{tabular}




\section{BELEZA EM 140 CARACTERES: UM ESTUDO SOBRE O COMPORTAMENTO DO CONSUMIDOR DE COSMÉTICOS BRASILEIROS NO TWITTER}

\begin{tabular}{|l|l|}
\hline Dissonância cognitiva & Dúvida ou falta de informação \\
\hline Sugestão, citação, indicação & Menção da marca sem que haja posicionamento explícito \\
\hline Expectativa & Interesse por evento futuro \\
\hline FF (Follow Friday) & $\begin{array}{l}\text { Ferramenta para indicação do perfil de algum usuário do Twitter } \\
\text { como interessante para ser disseminado aos "seguidores" do } \\
\text { emissor da mensagem }\end{array}$ \\
\hline Humor, saudações & Piadas, saudações desejando um bom dia \\
\hline
\end{tabular}

Quadro 4: Tipo de comportamento possível de identificar no tweet.

No Quadro 5 aborda-se três elementos clássicos do Mix de Marketing, conforme proposto por McCarthy (1982) e Kotler (2000) - produto, preço e praça. Nessa análise também foram inseridas a imagem da empresa e seu relacionamento com os clientes.

\begin{tabular}{|l|l|}
\hline \multicolumn{2}{|l|}{ Citação de elementos do Mix de Marketing } \\
\hline Produto & Qualidades do produto (cheiro, design, textura, cor) \\
\hline Marca & Imagem, comunicação \\
\hline Distribuição & $\begin{array}{l}\text { Ponto de venda (atendimento, espaço físico, indicação } \\
\text { como ponto de referência), entrega, revista para } \\
\text { divulgação ou venda direta }\end{array}$ \\
\hline Preço & $\begin{array}{l}\text { Custo e valor } \\
\text { Relacionamento com o cliente }\end{array}$ \\
\hline $\begin{array}{l}\text { Informação direta, resposta ao cliente, cursos } \\
\text { disponibilizados aos clientes }\end{array}$ \\
\hline
\end{tabular}

Quadro 5: Presença dos elementos do Mix de Marketing de acordo com a abordagem elaborada para a pesquisa

O objetivo do questionamento sobre o mix de produtos indicado pelos tweets foi identificar os principais produtos de cada marca, para que a informação possa auxiliar na identificação dos pontos fortes e fracos do mix de produtos. O Quadro 6 apresenta os tipos de produtos avaliados:

\begin{tabular}{|l|l|l|l|}
\hline Menção a produtos específicos \\
\hline Mãos, pés & Cabelo & Maquiagem & Sabonetes, desodorantes \\
\hline Perfumes & Tratamento Corpo & Tratamento rosto & Masculino \\
\hline Infantil & Sugestão novo produto & Outro & \\
\hline
\end{tabular}

Quadro 6: Menção a algum produto específico da empresa

Caso nos tweets analisados houvesse a citação de um ou mais produtos da linha da empresa, considerou-se para efeito dessa pesquisa aquele que foi enfatizado ou, caso todos tenham igual apresentação, aquele que foi citado primeiramente. No caso da menção de um $k i t$, sem identificar o tipo de produto, a marcação foi feita no item "outros".

Para mensurar o caráter promocional ou indicativo de mídia alternativa dos posts, foram considerados apenas os links explícitos, ou seja, cujo conteúdo pode ser identificado sem que haja necessidade de acessar seu conteúdo. A maioria dos tweets com links utilizam os encurtadores de URLs (Uniform Resource Locator ou Localizador-Padrão de Recursos, que são os endereços dos sites), os serviços disponíveis na internet que permitem encurtar endereços www a fim de serem facilmente inseridos nos 140 caracteres disponíveis para cada mensagem (TELLES, 2010). O Quadro 7 apresenta as opções de identificação de promoção ou link para outras mídias 
Caráter promocional ou indicativo de mídia alternativa

Link outra mídia da empresa ou canal de Link para mídia de terceiro (blog, site)

contato

Promoção da empresa de cosméticos

Promoção de terceiro

Quadro 7: Promoção ou chamada para link da empresa ou de terceiro

Aos dados coletados foram atribuídos os valores de zero ou um, sendo que um demonstra a presença da resposta específica a uma das perguntas formuladas, característica da aplicação da escala ordinal de classificação dos objetos. Esse tipo de escalonamento indica a posição relativa de um objeto perante os demais abordados (MALHOTRA, 2006). Além da abordagem comparativa, foram utilizados filtros disponibilizados pelo software Microsoft Excel que permitem combinar os dados, por exemplo: verificar a quantidade de tweets emitidos por alguém do sexo feminino posicionando-se negativamente quanto a qualidade de produtos para maquiagem.

\section{RESULTADOS}

A análise comparativa pareada dos dados coletados e tabulados auxiliou na identificação da quantidade de respondentes que citaram um estímulo ao invés de outro (MALHOTRA, 2006).

\subsection{Avaliação geral dos resultados obtidos}

A Tabela 1 apresenta os emissores das mensagens, ou seja, aqueles que postaram alguma informação no Twitter mencionando as marcas alvo deste estudo:

Tabela 1: Emissores das mensagens

\begin{tabular}{llll}
\hline Emissor da mensagem & & & \\
\hline Marca avaliada & Empresa de cosméticos & Rede & Total de Tweets \\
\hline Akakia & 260 & 71 & $\mathbf{3 3 1}$ \\
Boticário & 0 & 2831 & $\mathbf{2 8 3 1}$ \\
Contém 1g & 10 & 281 & $\mathbf{2 9 1}$ \\
Granado & 9 & 310 & $\mathbf{3 1 9}$ \\
Total & $\mathbf{2 7 9}$ & $\mathbf{3 4 9 3}$ & $\mathbf{3 7 7 2}$ \\
\hline
\end{tabular}

Fonte: dados primários obtidos pelo Twitter Advanced Search/2010

Pode-se perceber que há grandes diferenças entre as organizações do segmento de cosméticos na consideração das mensurações postadas no microblogging. De uma forma geral, a Akakia demonstra alta atividade, Contém 1g e Granado atuam no Twitter de forma discreta, postando informações pontuais e O Boticário mantém-se em silêncio no canal de comunicação, mas com sua imagem forte no mercado obteve o maior número de inserções citando sua marca na rede. Esse posicionamento vem contra o exposto por Telles (2010, p. 160) que citou a mesma empresa como atuante no Orkut, um outro tipo de rede social:

"No Orkut, O Boticário descobriu histórias curiosas, como a de Laura

Tupinambá, uma consumidora fã da deocolônia "One of Us", que 
juntou sua voz a de outros 200 consumidores (...) para reclamar da descontinuação da deocolônia pela empresa. Em vez de virar as costas para a consumidora, $O$ Boticário tratou rapidamente de entrar em contato com ela e explicar as razões da descontinuação do produto."

A ausência da empresa no Twitter é percebida pelo consumidor, conforme manifestação a seguir:

usuária 1: O \#boticário não tem twitter??

Jul 9, 2010 04:56 PM GMT $\cdot$ via web $\cdot \underline{\text { Reply }} \cdot \underline{\text { View Tweet }}$

A Tabela 2 apresenta noção de qual gênero do público demonstra maior interesse nas marcas de cosméticos mencionadas.

Tabela 2: Emissores das informações

\begin{tabular}{lllll}
\hline \multicolumn{1}{l}{ Gênero presumível do emissor da informação } & & \\
\hline Marca & Feminino & Masculino & Pessoa Jurídica & Sem indicação \\
\hline Akakia & 40 & 5 & 281 & 5 \\
\hline Boticário & 1344 & 441 & 632 & 414 \\
Contém 1g & 209 & 26 & 14 & 42 \\
Granado & 203 & 39 & 36 & 41 \\
\hline Total & $\mathbf{1 7 9 6}$ & $\mathbf{5 1 1}$ & $\mathbf{9 6 3}$ & $\mathbf{5 0 2}$ \\
\hline
\end{tabular}

Fonte: dados primários obtidos pelo Twitter Advanced Search/2010

Nitidamente, o público feminino é o maior "postador" de mensagens no Twitter quanto às marcas objetos desse estudo, com exceção do caso da Akakia Rio de Janeiro que, ao incentivar a promoção do dia dos pais postou mais de 200 tweets no dia 16 de julho, conforme exemplifica o tweet abaixo:

akakiarj: @usuário 2 Promoção de Dia dos Pais AKAKIA RJ. Aproveite, seu pai ganha e você também! http://tinyurl.com/23jld35 (expand) \#Promo Jul 16, 2010 09:03 PM GMT $\cdot$ via web $\cdot \underline{\text { Reply }} \cdot \underline{\text { View Tweet }}$

Ainda, $\mathrm{O}$ Boticário teve um alto número de posts masculinos devido à proximidade de data temática do Dia do Homem, divulgada com grande ênfase na televisão e nos pontos de venda da marca:

usuário 3: Dia 15 de julho é dia do homem, nem sabia q existia isso.Foi num anúncio da boticário q eu vi, nada mais adequado ñ?

Jul 5, 2010 09:38 PM GMT $\cdot$ via web $\cdot \underline{\text { Reply }} \cdot \underline{\text { View Tweet }}$

$\mathrm{Na}$ Tabela 3 são apresentados os resultados da avaliação do teor da informação postada, destacando elementos de sua conotação. A análise destes dados caracteriza o comportamento das pessoas que registraram suas opiniões. 
Tabela 3: Tipo de comportamento

\begin{tabular}{|c|c|c|c|c|c|c|c|c|c|}
\hline \multicolumn{10}{|c|}{ Comportamento } \\
\hline Marca & $\begin{array}{l}\text { Positiv } \\
\text { o }\end{array}$ & $\begin{array}{l}\text { Negativ } \\
\text { o }\end{array}$ & $\begin{array}{l}\text { Declaraçã } \\
\text { o compra }\end{array}$ & $\begin{array}{l}\text { Intençã } \\
\text { o } \\
\text { compra }\end{array}$ & $\begin{array}{l}\text { Dúvid } \\
\text { a }\end{array}$ & $\begin{array}{l}\text { Sugestã } \\
\text { o }\end{array}$ & $\begin{array}{l}\text { Expectativ } \\
\text { a }\end{array}$ & $\begin{array}{l}\mathbf{F} \\
\mathbf{F}\end{array}$ & $\begin{array}{l}\text { Humo } \\
\mathbf{r}\end{array}$ \\
\hline Akakia & 25 & 1 & 1 & 0 & 5 & 274 & 3 & 10 & 8 \\
\hline $\begin{array}{l}\text { Boticári } \\
\text { o }\end{array}$ & 420 & 309 & 154 & 122 & 102 & 1483 & 83 & 0 & 90 \\
\hline $\begin{array}{l}\text { Contém } \\
1 \mathrm{~g}\end{array}$ & 83 & 40 & 18 & 24 & 35 & 55 & 16 & 0 & 10 \\
\hline Granado & 107 & 11 & 23 & 3 & 17 & 95 & 5 & 0 & 3 \\
\hline Total & 635 & 361 & 196 & 149 & 159 & 1907 & 107 & 10 & 111 \\
\hline
\end{tabular}

Fonte: dados primários obtidos pelo Twitter Advanced Search /2010

Os aspectos comportamentais avaliados são altamente subjetivos, pois em alguns casos a conotação pode vir de uma simples combinação de caracteres, como no caso abaixo, que tem posicionamento negativo em relação à marca representado pela expressão :(. Reforça-se aqui o exposto por Kozinets (2001) ao mencionar o entrée cultural como necessário para o entendimento do universo pesquisado, formas de comunicação, termos usuais:

usuária 4: @usuária 5 o meu é do boticario :(

Jul 17, 2010 05:22 AM GMT $\cdot$ via $\underline{\text { web }} \cdot \underline{\text { Reply }} \cdot \underline{\text { View }}$ Tweet $\cdot$ Show Conversation

De um modo geral, a indicação ou sugestão da empresa são os comportamentos mais frequentes nos comentários do Twitter. Sem conotação positiva ou negativa, sugere-se o nome da empresa individualmente ou ligada a outras marcas, como no exemplo a seguir:

usuária 6: Contem 1g: http://wp.me/pPIjg-cB

Jul 6, 2010 08:04 PM GMT $\cdot$ via WordPress.com $\cdot \underline{\text { Reply }} \cdot \underline{\text { View Tweet }}$

Nas quatro empresas avaliadas, o posicionamento positivo superou o posicionamento negativo em aproximadamente setenta e cinco por cento, o que sugere que se realiza nas comunidades virtuais o denominado boca-a-boca. Kotler ao ser entrevistado por Telles (2010) disse que "as empresas devem, principalmente, entregar o que prometem e oferecer um excelente serviço. É sobre isso, na verdade, que os consumidores falam nas redes sociais”.

De acordo com pesquisa sobre o comportamento feminino nas redes sociais, percebeuse que a brasileira moradora dos Estados Unidos comenta mais do que outras de origem latina (argentina, mexicana e espanhola) sobre experiências de consumo nas redes sociais. A pesquisa afirma que a maioria dos dados são sobre posicionamentos positivos (COMPORTAMENTO FEMININO, 2010), o que se confirma pela presente pesquisa: ao utilizar o filtro do Excel obteve-se a informação de que 259 posts emitidos por mulheres sobre a empresa $\mathrm{O}$ Boticário eram positivos, enquanto 171 tinham caráter negativo. 


\section{BELEZA EM 140 CARACTERES: UM ESTUDO SOBRE O COMPORTAMENTO DO CONSUMIDOR DE COSMÉTICOS BRASILEIROS NO TWITTER}

Na Tabela 4 identifica-se três elementos formadores do Mix de Marketing (Produto, Preço e Praça) além da imagem da marca e o relacionamento com os clientes. Esclarece-se que o $4^{\circ} \mathrm{P}$ (promoção) que não foi inserido nessa tabela está explicitado na Tabela 6.

Tabela 4: Citação de algum dos elementos do Mix de Marketing

Elementos do Mix de Marketing

\begin{tabular}{llllll}
\hline Marca & Produto & Marca & Distribuição & Preço & $\begin{array}{l}\text { Relacionamento } \\
\text { com o cliente }\end{array}$ \\
\hline Akakia & 17 & 21 & 0 & 1 & 19 \\
Boticário & 304 & 940 & 119 & 24 & 94 \\
Contém 1g & 76 & 56 & 44 & 22 & 30 \\
Granado & 92 & 46 & 39 & 2 & 12 \\
Total & $\mathbf{4 8 9}$ & $\mathbf{1 0 6 3}$ & $\mathbf{2 0 2}$ & $\mathbf{4 9}$ & $\mathbf{1 5 5}$ \\
\hline
\end{tabular}

Fonte: dados primários obtidos pelo Twitter Advanced Search/2010

A marca é o item que apresenta um maior número de menções nas mensagens postadas, um pouco mais de cinquenta por cento. Ela pode ser o ativo mais forte de uma organização, pois é uma promessa de entrega de produtos e serviços com um certo padrão de qualidade nos seus atributos, benefícios, valores, cultura e personalidade (KOTLER, 2000). As mensagens a seguir reforçam essa afirmação:

usuário 7: Benditos sejam os donos da Granado! Não tem nada tão bom como tomar banho com os produtos da Granado. Saio outra pessoa! ol Jul 7, 2010 04:33 AM GMT $\cdot$ via web $\cdot \underline{\text { Reply }} \cdot \underline{\text { View Tweet }}$

Além das referências sobre a marca, têm maior quantidade as considerações relativas ao produto em si, suas características intrínsecas e extrínsecas, conforme mensagem em destaque:

usuário 8: Ganhei um perfume F399 Sports @akakia.Muito bom!

Jul 6, 2010 07:11 PM GMT $\cdot$ via web $\cdot \underline{\text { Reply }} \cdot \underline{\text { View Tweet }}$

A indicação do tipo de produto do mix que cada empresa disponibiliza ao seu consumidor serve como balizador do posicionamento de mercado de cada uma delas, conforme apresentado na Tabela 5.

Tabela 5: Citação de algum produto ou linha específica

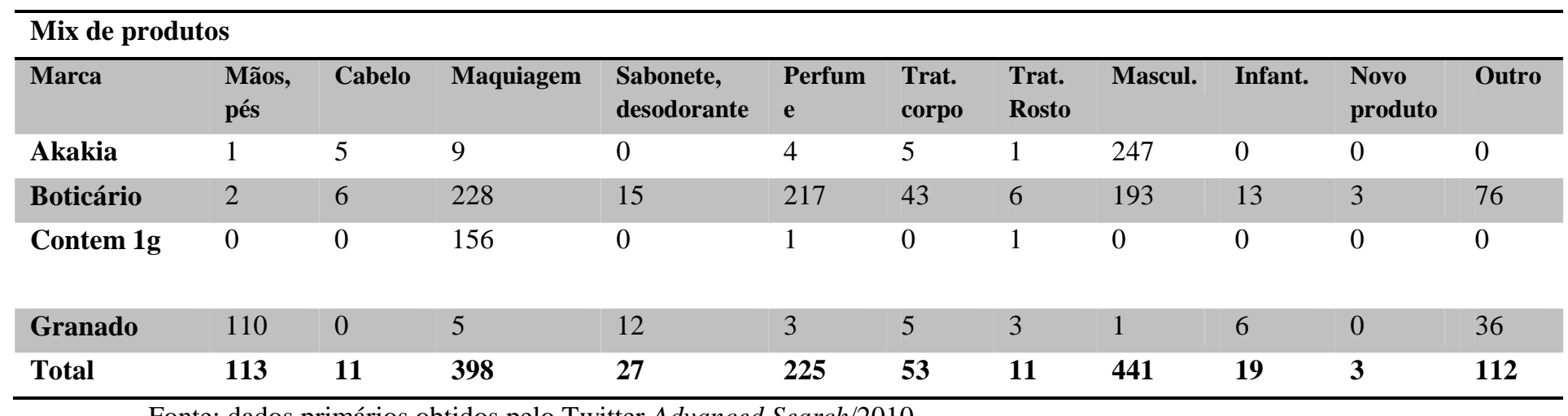

Fonte: dados primários obtidos pelo Twitter Advanced Search/2010 
A Akakia é uma empresa lembrada pela perfumaria e sua franqueada do Rio de Janeiro, fez divulgação da linha de produtos masculinos com foco nos presentes do Dia dos Pais.

A empresa O Boticário pode ser considerada uma marca expressiva em produtos de maquiagem e perfumaria, com força também nos produtos para o público masculino, cuja ênfase se deu devido à proximidade do período pesquisado ao Dia do Homem e das campanhas para o Dia dos Pais.

A Contém 1g tem abordagem no Twitter quanto a seus produtos de maquiagem, o que está de acordo com o objetivo apresentado em seu site.

A Granado tem como produto mais comentado a "cera nutritiva para unhas e cutículas", cujos comentários são, quase todos, positivos quanto ao efeito do produto e suas características.

Dois aspectos muito relevantes nas mídias sociais, por isso dissociados dos elementos do mix de Marketing e apresentados na Tabela 6, são a promoção e a utilização de hipertexto que, segundo Telles (2010) é a "escrita de texto não seqüencial, que permite ao usuário fazer a conexão entre informações e documentos por meio de palavras que contém ligações com outros textos".

Tabela 6: Promoção ou link para outra mídia

\begin{tabular}{l|l|l|l|l}
\hline Promoção ou link para outra mídia (da empresa ou de terceiros) & & \\
\hline Marca & $\begin{array}{l}\text { Link outra mídia } \\
\text { da empresa }\end{array}$ & $\begin{array}{l}\text { Promoção } \\
\text { empresa }\end{array}$ & $\begin{array}{l}\text { Link para mídia } \\
\text { de terceiro }\end{array}$ & $\begin{array}{l}\text { Promoção } \\
\text { terceiro }\end{array}$ \\
\hline Akakia & 23 & 239 & 16 & 1 \\
\hline Boticário & 20 & 7 & 67 & 1116 \\
Contém 1g & 0 & 2 & 10 & 9 \\
Granado & 7 & 1 & 49 & 28 \\
Total & $\mathbf{5 0}$ & $\mathbf{2 4 9}$ & $\mathbf{1 4 2}$ & $\mathbf{1 1 5 4}$ \\
\hline
\end{tabular}

Fonte: dados primários obtidos pelo Twitter Advanced Search/2010

A Akakia pela franquia do Rio de Janeiro utilizou uma promoção própria para o dia dos pais e dirigiu-a a diversas pessoas individualmente, totalizando 239 posts, conforme exemplo a seguir:

akakiarj: @usuário 9 Promoção de Dia dos Pais AKAKIA RJ. Aproveite, seu pai ganha e você também! http://tinyurl.com/23jld35

(expand) \#Promo

Jul 16, 2010 09:03 PM GMT $\cdot$ via web $\cdot \underline{\text { Reply }} \cdot \underline{\text { View Tweet }}$

O Boticário, por sua vez, tem grande representação da sua marca nas promoções de terceiros, o que significou, inclusive, mais de $30 \%$ dos posts referentes à marca. Um deles foi assim postado:

usuária 10: \#sorteio de um 1 kit do boticario. SIGA @PointPromocoes $\boldsymbol{e}$ @WebStudioCom para concorrer: http://migre.me/UrPI

Jul 9, 2010 11:17 PM GMT $\cdot$ via web $\cdot \underline{\text { Reply }} \cdot \underline{\text { View Tweet }}$ 


\subsection{Avaliação individual das empresas}

Diversas análises foram feitas quanto a comportamentos padrão, curiosidades e estratégias observadas no estudo individualizado de cada marca e que são elencadas abaixo:

\section{Empresa Akakia}

A empresa teve dois perfis considerados para essa pesquisa: @ AKAKIA e @akakiarj.

A marca busca manter o relacionamento com "blogueiras" (pessoas que mantêm blogs sobre maquiagens, utilização de produtos e análise da qualidade dos mesmos) em Recife, que são irradiadoras de opiniões sobre cosméticos. Exemplificando esta afirmação:

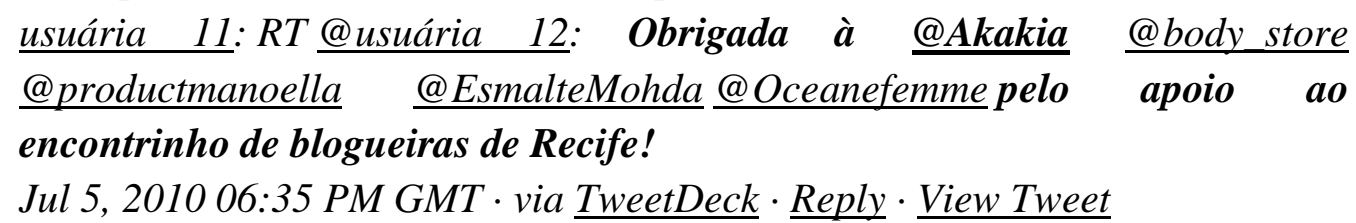

A empresa, pelo perfil @akakiarj, aproveitou a proximidade do Dia dos Pais para enviar promoção individualmente para determinadas pessoas (possivelmente seus seguidores): akakiarj: @ usuária 13 Promoção de Dia dos Pais AKAKIA RJ. Aproveite, seu pai ganha e você também! http://tinyurl.com/23jld35 (expand) \#Promo Jul 16, 2010 08:53 PM GMT $\cdot$ via web $\cdot \underline{\text { Reply }} \cdot \underline{\text { View Tweet }}$

A empresa Akakia retwittou comentários positivos a seu respeito e abordou assuntos diferentes de sua própria natureza ao sugerir temas como moda e atualidades, conforme mensagem a seguir:

AKAKIA: Aproveita! :) RT @usuária 14: @ akakia ontem usei o hidratante flor de lotus que ganhei no Encontro (...) e adorei, ele é maravilhoso...

Jul 6, 2010 07:39 PM GMT $\cdot$ via $\underline{\text { TweetDeck }} \cdot \underline{\text { Reply }} \cdot \underline{\text { View Tweet }}$

Nos finais de semana quando a empresa não emite seus tweets, a quantidade de mensagens contendo o nome da marca cai significativamente.

\section{Empresa O Boticário}

Um dos pontos positivos mencionados sobre os pontos de venda da referida empresa são as maquiagens feitas pelas consultoras da marca, conforme o exemplo:

usuária 15: Aiai, comprei um milhao de coisas. Mas o mais legal foi a mulher do boticário me achar linda e fazer um super make up em mim!

Jul 5, 2010 09:54 PM GMT $\cdot$ via web $\cdot \underline{\text { Reply }} \cdot \underline{\text { View Tweet }}$

A Rádio Transamérica, pelo perfil @TEsportes, fez inúmeras promoções aos ouvintes e seguidores com sorteio de kits O Boticário. Aqui percebe-se a complementaridade das mídias (rádio e internet/mídias sociais):

tesportes: Outra promoção que tem no programa de hoje é do O Boticário, que vai sortear quatro kits para homens em homenagem ao dia do homem.

Jul 5, 2010 08:42 PM GMT $\cdot$ via web $\cdot \underline{\text { Reply }} \cdot \underline{\text { View Tweet }}$ 
A informação que O Boticário estaria ampliando seu mercado para a venda direta foi bastante divulgada por tweets e retweets com o termo "expansão de O Boticário", conforme mensagem abaixo:

usuário 16: Especial: Expansão de O Boticário agrega ruas e shoppings http://migre.me/UXO4

Jul 7, 2010 01:43 PM GMT $\cdot$ via $\underline{\text { web }} \cdot \underline{\text { Reply }} \cdot \underline{\text { View Tweet }}$

\section{Empresa Contém 1g}

A organização tem como seus perfis considerados para esta pesquisa: @contem1gbelem, @contem1gVix, @contem1gWS.

O lançamento da loja conceito da Contém 1g no Morumbi Shopping, em SP, teve boa repercussão no Twitter, como pode-se demonstrar nesta mensagem:

usuária 17: Já tão sabendo que vai inaugurar a nova loja da Contém $1 \mathrm{~g}$ no Shopping Morumbi- SP? A inauguração é Amanhã, às 19h! Super válido! Jul 6, 2010 07:00 PM GMT $\cdot$ via web $\cdot \underline{\text { Reply }} \cdot \underline{\text { View Tweet }}$

Identificou-se reclamações relacionadas quanto aos preços praticados pela marca, quando comparados a outras marcas. Uma das menções foi:

usuária 18: Olha eu acho um ABSURDo a Contém $1 \mathrm{~g}$ estar vendendo batons à 62 reais. Sendo q a MAC é 69. Hellooooo

Jul 13, 2010 01:41 AM GMT $\cdot$ via web $\cdot \underline{\text { Reply }} \cdot \underline{\text { View Tweet }}$

E também foi apontada reclamação por falta de comunicação interna, como a descrita a seguir:

usuária 19: Contém 1g manda promoção por email mas na loja ninguém nunca ouvir falar. Nem do lançamento nem da promoção. BOA!

Jul 16, 2010 10:28 PM GMT $\cdot$ via $\underline{\text { TweetDeck }} \cdot \underline{\text { Reply }} \cdot \underline{\text { View Tweet }}$

\section{Empresa Granado}

A organização teve como perfil utilizado: @granado_oficial.

Foram identificadas citações com o nome Granado sem relação com a marca, significando sobrenome, ou jogos, como esta:

usuária 20: RT @usuária 21: Córdoba, onde Ernesto "Che" Guevara e AlbertoGranado saíram de motocicleta há mais de 50 anos: http://bit.ly/cXZN2g (expand) Os Caminhos de Che

Jul 13, 2010 03:41 PM GMT $\cdot$ via TweetDeck $\cdot \underline{\text { Reply }} \cdot \underline{\text { View Tweet }}$

O produto líder em citações da Granado sem dúvida é a cera nutritiva para unhas e cutículas, que pertence à Linha Pink também muito mencionada, como segue abaixo:

usuária 22: @usuário 23 Olha só: http://bit.ly/cldUeL (expand) Eu estou usando a cera nutritiva da Granado. 


\section{Jul 5, 2010 06:51 PM GMT $\cdot$ via Echofon $\cdot \underline{\text { Reply }} \cdot \underline{\text { View Tweet }} \cdot$ Dhow} Conversation

Poucas pessoas mencionam a linha Pet da Granado - mas quando mencionada, o posicionamento é positivo, conforme verificado nesta mensagem:

usuária 24: @usuária 25 acabei de descobrir q tem linha "pet" na granado! e abriu a loja no park shopping! bina vai ficar cheirosíssima!!

Jul 14, 2010 05:20 PM GMT . via web $\cdot \underline{\text { Reply }} \cdot \underline{\text { View Tweet }} \cdot$ Phow Conversation

Foram identificadas reclamações sobre a dificuldade de encontrar os produtos da Granado em algumas mensagens postadas. Uma delas diz:

usuária 26: Depois de muito procurar, finalmente consegui achar a cera dagranado para unhas e cutículasna@drogaria_araujo

Jul 7, 2010 12:04 PM GMT $\cdot$ via web $\cdot \underline{\text { Reply }} \cdot \underline{\text { View Tweet }}$

\section{CONCLUSÕES}

As mídias sociais ainda são uma forma de comunicação considerada confusa pelas empresas, há dúvidas sobre como se comunicar, estabelecer relações, reagir a comentários negativos, dentre outras questões. Percebe-se que não há uma equivalência no conteúdo dos tweets, pois cada empresa atua de forma diferenciada. O'Reilly e Milstein (2009, p. 109), afirmam que

"o segredo da mídia social é que não se trata apenas de você, seu produto ou sua historia, mas de como você agrega valor às comunidades das quais participa. Se quiser causar um impacto positivo, esqueça o que você pode tirar da mídia social e comece a pensar em como você pode contribuir para melhorá-la. Mais interessante ainda é que, quanto mais valor você agregar à comunidade, mais valorizado ficará."

A empresa Akakia é a que apresenta maior intimidade com esse "jornal mundial", pois reproduz comentários positivos à sua identidade e aborda outros assuntos, como moda, variedades e saúde.

A Contém $1 \mathrm{~g}$ atua no Twitter trazendo informações da empresa e retwittando posts de consumidores.

A Granado também retransmite mensagens de clientes, bem como dá dicas de beleza e "conversa" com seus clientes.

Percebe-se pela análise dos dados que:

- A maior fonte de disseminação das marcas de cosméticos é a citação do nome sem posicionamento ou referindo-se às promoções para sorteio de produtos, seja da empresa ou de terceiros. 
- Em seguida, os posicionamentos positivos têm destaque na proporção de, em média, $75 \%$ em relação aos posts negativos. As pessoas querem dividir suas experiências na rede. Segundo O'Reilly e Milstein (2009, p. 17) "as pessoas querem saber o que os outros estão fazendo (sem ter que perguntar), o que causa a impressão de uma leve, mas significativa conexão."

- O Twitter também é utilizado para expressar descontentamento com qualquer aspecto relativo à marca, sejam problemas na distribuição, elementos do produto que causem descontentamento, atendimento insatisfatório, dentre outros aspectos.

- A declaração e a intenção de compra referem-se principalmente à pergunta tema do Twitter "o que está acontecendo" e assim as pessoas se comunicam com seus seguidores informando o que adquirem ou querem adquirir.

- Dúvidas, expectativas, Follow Fridays e humor: aparecem em menor escala, mas também estão presentes nas postagens, na proporção de aproximadamente $10 \%$ das mensagens que continham noção de comportamento do consumidor (foram 387 mensagens num contexto total de 3635 mensagens com teor comportamental).

Conseguiu-se identificar o que foi proposto na pergunta inicial no intuito de colaborar com o conhecimento desse novo universo que é apresentado à sociedade contemporânea, o Twitter. Ocorre que ainda restam alguns aspectos não elencados nesse trabalho, que podem ser objeto de estudo para futuras pesquisas, como por exemplo, analisar as formas mais usuais de postagem das mensagens no Twitter (web, tweet deck, Facebook, etc), a frequência e relação com que são postadas respostas ou repplies.

Não restam dúvidas que as mídias sociais vieram para ficar e serão diversificadas e aperfeiçoadas, e as organizações aos poucos vão aprendendo com erros e acertos a mostrar suas características sociais para estabelecerem relacionamento de mútua confiança com os clientes. A confiança se estabelece pelo reflexo dos valores organizacionais comunicados de forma uníssona pelas estratégias de comunicação e esforços promocionais (MANGOLD \& FAULDS, 2009) obtidos com a comunicação entre setores internos diversos.

\section{REFERÊNCIAS}

AMARAL, Adriana; NATAL, Geórgia; VIANA, Lucina. Netnografia como aporte mercadológico da pesquisa em comunicação digital. In: Cibercultura. Famecos/PUCRS, n. 20. Porto Alegre: Famecos/PUCRS, 2008. p. 34-40.

COMPORTAMENTO FEMININO nas redes sociais. Disponivel em <http://www.portaldoconsumidor.gov.br/noticia.asp?busca=sim\&id=16643 > Acesso em 14 Jul 2010.

DIAMOND, Jay; DIAMOND, Ellen. The world of fashion. $4^{\text {th }}$ ed. New York: Fairchild Books, Inc, 2008. p. 340-366. 
DIMANTAS, Hernani. Comunidades virtuais: heterodoxia informacional. In: PEREZ, Clotilde; BARBOSA, Ivan Santo, orgs. Hiperpublicidade: atividades e tendências. São Paulo: Thomson Learning, 2008. p. 380-397.

GARCILLÁN, Mencia de. Marketing para cosméticos: uma abordagem internacional. Tradução Vertice Translate. Rev. Técn. Rose Ghachache. São Paulo: Thomson Learning, 2008. Série Profissional.

KOTLER, Philip. Administração de Marketing: a edição do novo milênio. Tradução Bazán Tecnologia e Lingüística; revisão técnica Arão Sapiro. 10. ed. São Paulo: Prentice Hall, 2000.

KOZINETS, Robert V. The field behind the screen: using netnography for marketing research in online communities. Evanston: J. L. Kellogg Graduate School of Management, 2001.

Click to connect: netnography and tribal advertising. Journal of Advertising Research, 2006.

MCCARTHY, E. Jerome. Marketing. Colaboração Andrew A. Brogowicz. Tradução José Ricardo Brandão Azevedo. Rio de Janeiro: Campus, 1982.

MCKENNA, Regis. Marketing de relacionamento. Tradução Outras Palavras. Rio de Janeiro: Campus; São Paulo: Publifolha, 1999.

MALHOTRA, Naresh. Pesquisa de marketing: uma orientação aplicada. Porto Alegre: Bookman, 2006. 720 p.

MANGOLD, W. Glynn; FAULDS, David J. Social media: the new hybrid element of the promotion mix. Kelley School of Business, Indiana University: Business Horizons, n. 52, p. 357-365, 2009.

O’REILly, Tim; MILSTEIN, Sarah. Desvendando o Twitter. Tradução Eduardo Fráguas. São Paulo: Digerati Books, 2009.

RECUERO, Raquel. Redes sociais na internet. Porto Alegre: Sulina, 2009. Coleção Cibercultura.

STONE, Merlin, WOODSTOCK, Neil. Marketing de relacionamento. Tradução Luiz Liske. São Paulo: Littera Mundi, 1998.

TAPSCOTT, Don; WILLIAMS, Anthony D. Wikinomics: como a colaboração em massa pode mudar o seu negócio. Tradução Marcello Lino. Rio de Janeiro: Nova Fronteira, 2007.

TELLES, André. Orkut.com. São Paulo: Editora Landscape, 2006. 
A revolução das mídias sociais: cases, conceitos, dicas e ferramentas. São Paulo: M. Books do Brasil, 2010.

VERGARA, Sylvia Constant. Métodos de pesquisa em administração. 3 ed. São Paulo: Atlas, 2008. 